\title{
The Impact of Parental Psychiatric Symptoms and Parent-Child Relationships on Behavioural and Emotional Problems in Newly- Diagnosed Toddlers and Preschool Children with Autism Spectrum Disorders
}

\author{
Ayhan Bilgiç and Necati Uzun \\ Department of Child and Adolescent Psychiatry, Meram School of Medicine, Necmettin Erbakan University, \\ Turkey
}

\begin{abstract}
Background: Emotional and behavioural problems occur at a high rate in children with autism spectrum disorders (ASD). These problems are associated with a broad range of risk factors such as parental psychopathology and family environment in school-age children and adolescents. However, limited information is available about these phenomena in toddlers and preschool children. This cross-sectional study examined the association of maternal and paternal psychiatric symptoms and mother-child relationships with emotional and behavioural problems and socioemotional competence of newly-diagnosed young children with ASD.
\end{abstract}

Method: Autistic symptoms, developmental level, and mother-child relationship of children were evaluated. Parents completed a checklist on child behavioural and emotional problems, and individual questionnaires on their own mental health.

Results: Participants were 35 children with ASD aged $18-53$ months, referred to an infant mental health clinic. Maternal hostility and poor mother-child relationships have been found to be independently associated with emotional and behaviour problems in these children.

Conclusions: This study suggests that maternal hostility and mother-child relationship problems may play a role for the development of emotional and behaviour problems in toddlers and preschool children with ASD.

Keywords: ASD, toddlers, preschool children, emotional problems, behavioural problems, parents.

\section{INTRODUCTION}

Research indicates that emotional and behavioural disturbances are prevalent in children and adolescents with autism spectrum disorders (ASD) $[1,2]$. These disturbances are associated with a variety of risk factors such as parental psychopathology, child characteristics and family environment in school-age children and adolescents $[3,4]$. However, less is known regarding these phenomena in young children with ASD.

The burden of raising a child with ASD may negatively affect both maternal and paternal mental health $[5,6]$. Many studies demonstrated that parents of children with ASD especially at risk for experiencing greater levels of depressive and anxiety symptoms [5, 6]. Despite there is a reciprocal relationship between parents' and child's psychiatric status, however, less data is available regarding the potential effects of parental mental health on children with ASD. Treatment for children with ASD seems to be more effective in early period of life [7]; therefore, the

*Address correspondence to this author at the Department of Child and Adolescent Psychiatry, Necmettin Erbakan Universitesi, Meram Tip Fakultesi, Çocuk ve Ergen Psikiyatrisi AD 42090, Meram/Konya, Turkey;

Fax: +90 332 2236859; E-mail: bilgicayhan@yahoo.com importance of putative effect of parental psychiatric status on children with ASD may be higher in very young children.

Positive parent-infant interactions has predicted less behavioral and emotional problems for preschool and school-age children in the general population $[8,9]$. Tough the relationship between parent-infant interactions and behavioral and emotional problems has not been well-known in children with ASD, one study showed that the quality of early dyadic interaction between parent and infant is related with core ASD symptoms at-risk infants [10]. Thus, the investigation of the relationship between parent-child interaction and behavioral and emotional problems of young children with ASD may be beneficial.

In this chart review, we aimed to examine the relationships of maternal and paternal psychiatric symptoms and mother-child relationships with socioemotional and behavioural problems and socioemotional competence in newly-diagnosed toddlers and preschool children with ASD. These relationships were examined after accounting for the severity of autistic symptoms and the developmental age of children. The main hypothesis of this study was that the severity of parental psychiatric symptoms and poor mother-child relationships would be related to 
higher levels of socioemotional and behavioural problems, and lower levels of socioemotional competence in these children.

\section{METHODS}

\subsection{Participants and Procedures}

Approval for this retrospective chart review was obtained from the Institutional Review Board. The database of the Meram Faculty of Medicine, Toddlers and Preschooler Mental Health Outpatient Clinic was utilized to identify all newly diagnosed children with ASD. The study sample was comprised of children who met the DSM- 5 criteria for ASD. Diagnosis of the ASD was made by clinical interviews and observations of the child based on the DSM-5 criteria of this disorder. As part of their routine clinical evaluation, all children were evaluated based on the Diagnostic Classification: 0-3 Revised (DC:0-3R). The severity of autistic symptoms and developmental ages of children were assessed, and parents were asked to complete a battery of measures prior to their first visit.

The inclusion criteria included being from 18 to 60 months of age and having a new diagnosis of ASD according to the DSM-5 criteria. The exclusion criteria included the presence of a major physical or neurological illness (e.g., cardiac problems or epilepsy), and patients on pharmacological treatment or special training for ASD. In total, 35 ASD patients met the study criteria and their recorded clinical data were evaluated.

\subsection{Scales and Measures}

\section{Brief Infant and Toddler Social Emotional Assessment (BITSEA)}

The BITSEA is a 42 -item scale that screens early childhood socioemotional and behavioural problems and socioemotional competence [11]. The feature or behaviour described in each item is included in the problem or competence subscale. Higher total scores on the problem subscale (BITSEA/P) indicate a higher level of behavioural and emotional problems, and lower total scores on the competence subscale (BITSEA/C) indicate a lower level of competence. In this study, mothers completed the BITSEA. The Turkish translation and adaptation of the BITSEA was conducted by Karabekiroglu et al. [12].

\section{Brief Symptom Inventory (BSI)}

The BSI is an abbreviated form of the 90-item Symptom Checklist (SCL-90) [13]. The BSI contains 53 items and is rated on a scale from 0 to 4 . A standardization study of the Turkish version of the BSI yielded five distinct factors, namely, "anxiety", "depression", "negative self", "somatization" and "hostility" [14]. Higher scores indicate a higher possibility of a psychopathology. In this study, both mothers and fathers completed this instrument.

\section{Childhood Autism Rating Scale (CARS)}

The Childhood Autism Rating Scale (CARS) consists of 15 items, which are rated on a scale of $1-4$, with all the items contributing equally to one total score [15]. Children were evaluated with CARS via family interviews and child observations. Items on the scale pertain to interpersonal relationships, imitation, emotional response, body use, object use, adaptation to change, visual response, listening response, taste and smell responses, use of touch, fear/nervousness, verbal communication, non-verbal communication, activity level, level of intellectual response and general impressions [16].

\section{Ankara Developmental Screening Inventory (ADSI)}

The ADSI was developed for assessing developmental levels of Turkish children [17]. It is administered to the caregiver and consists of a total of 154 questions covering an age range from 0 to 60 months. The questions address different areas of development including cognitive language, fine motor abilities, gross motor abilities, and social and self-care skills subscales. The total score of these four subscales yields the general developmental score. In this study, only the general developmental score was used. Developmental delay levels were defined by dividing the developmental level score determined by the ADSI to normative data which were matched for their age.

\section{Parent-Infant Relationship Global Assessment Scale (PIR-GAS)}

The PIR-GAS is used to evaluate the quality of parent-child relationships in the DC:0-3R, which was designed for a systematic and developmentally-based approach to classify psychiatric problems in infants and toddlers in the first four years of life [18]. The PIR-GAS is rated by clinicians and assesses the global quality of parent-child relationships on a continuum from "well adapted" (100) to "grossly impaired" (0). In this study, the PIR-GAS was rated by an expert clinician with more than 10 years of clinical and research experience with infant mental health and ASD. 


\subsection{Statistical Analysis}

All analyses were performed with SPSS, Version 21.0 for Windows (SPSS, Inc., Chicago, IL, USA). The Pearson or Spearman correlation coefficients were calculated to examine the relationships between variables. Multivariable linear regression analyses were conducted to assess the determinants of BITSEA/P and BITSEA/C scores. A two-tailed $P$-value of $<0.05$ was considered to be statistically significant.

\section{RESULTS}

The mean age of the children was $31.9 \pm 8.4$ months, and the study group consisted of $28(80 \%)$ boys and $7(20 \%)$ girls. The mean CARS scores of the patients was $31.3 \pm 4.9$ (range: $22-44$ ). The PIR-GAS scores varied between 35 and 82 , and general developmental level/normative data, which was defined by the ADSI, were between $34 \%$ and $94 \%$. Results of the children's psychometric assessments are presented in Table 1.

Table 1: Mean CARS, PIR-GAS, BITSEA, ADSI, and Mothers' and Fathers' BSI Scores in Preschool Children with Autistic Spectrum Disorders $(n=35)$

\begin{tabular}{|l|c|}
\hline Psychometric assessments & Mean \pm SS \\
\hline \hline CARS & $31.3 \pm 4.9$ \\
PIR-GAS & $66.1 \pm 9.8$ \\
BITSEA & \\
Problem & $17.5 \pm 7.5$ \\
Competence & $10.0 \pm 3.7$ \\
ADSI & \\
Total score/ Normative data (\%) & $64.7 \pm 14.0$ \\
Mothers' BSI & \\
Depression & $14.0 \pm 9.9$ \\
Anxiety & $7.0 \pm 6.1$ \\
Negative self & $10.1 \pm 7.7$ \\
Somatization & $5.3 \pm 5.0$ \\
Hostility & $8.0 \pm 4.9$ \\
Fathers' BSI & \\
Depression & $9.8 \pm 9.7$ \\
Anxiety & $5.9 \pm 5.5$ \\
Negative self & $8.6 \pm 8.4$ \\
Somatization & $3.9 \pm 4.2$ \\
Hostility & $7.1 \pm 4.7$ \\
\hline
\end{tabular}

CARS: Childhood Autism Rating Scale, PIR-GAS: Parent-Infant Relationship Global Assessment Scale, BITSEA: Brief Infant and Toddler Social Emotional Assessment, ADSI: Ankara Developmental Screening Inventory, BSI: Brief Symptom Invertory.

Correlations between the BITSEA/P and BITSEA/C scores and other study variables were assessed.
BITSEA/P scores were positively correlated with the BSI depression $(r=0.49, p=0.003)$, anxiety $(r=0.41$, $p=0.014)$, negative self $(r=0.48, p=0.004)$, somatization $\left(r_{\mathrm{s}}=0.39, p=0.019\right)$, and hostility $(r=$ $0.49, p=0.003$ ) subscale scores of mothers. BITSEA/P scores were also positively correlated with the BSI anxiety $\left(r_{\mathrm{s}}=0.38, p=0.023\right)$, somatization $\left(r_{\mathrm{s}}=0.39, p\right.$ $=0.019)$, and hostility $(r=0.34, p=0.043)$ subscale scores of fathers; however, they were negatively correlated with PIR-GAS scores $(r=-0.42, p=0.013)$. BITSEA/C scores were positively correlated with the age of the patients $(r=0.35, p=0.039)$, but negatively correlated with the CARS scores $(r=-0.58, p<0.001)$.

Multivariate linear regression analyses (forward method) were used to test the predictors of the BITSEA/P and BITSEA/C scores (Table 2). The models contained the variables showing significant correlations with BITSEA/P and BITSEA/C scores as independent variables. Higher mothers' BSI hostility $(\beta=0.41, t=$ 2.73, $p=0.010)$ and lower PIR-GAS $(\beta=-0.31, t=$ 2.04, $p=0.049$ ) scores had significant regression relationships with the BITSEA/P scores $\left(R^{2}=0.33\right.$, adjusted $R^{2}=0.29$ ). With regard to BITSEA/C scores, only the CARS scores showed a significant regression relationship with the BITSEA/C scores $(\beta=-0.58, t=-$ $4.10, p<0.001, R^{2}=0.34$, adjusted $R^{2}=0.32$ ).

\section{DISCUSSION}

The results of this preliminary study showed that maternal hostility and poor mother-child relationships have associations with emotional and behaviour problems of newly-diagnosed toddlers and preschool children with ASD, after accounting for child autistic symptoms and developmental age, maternal depression, anxiety, somatization, self-esteem, and all paternal psychiatric symptoms. However, no relationship was found between parental mental health and mother-child relationships to the socioemotional competence of these children. Although the crosssectional design of this study precluded making causal inferences, our findings suggest that the evaluation of the maternal mental health and mother-child relationships may be valuable while addressing coexisting emotional and behavioural disturbances in very young children with ASD.

Previous evidence suggests that parental mental health may affect the behaviours of subjects with ASD from school-age until adulthood [19,20,21]. However, data concerning the impact of parental mental health on behaviour problems of toddlers and preschool 
Table 2: Results of Lineer Regression (Forward Stepwise) Predicting the BITSEA/P and BITSEA/C Scores $(\mathrm{n}=35$ )

\begin{tabular}{|c|c|c|c|c|c|c|c|c|}
\hline & B & SE $B$ & $\beta$ & $\mathbf{t}$ & p & $\begin{array}{l}\text { Confidence } \\
\text { Interval(95\%) }\end{array}$ & $\mathbf{R}^{2}$ & $\operatorname{Adj} \mathrm{R}^{2}$ \\
\hline \multicolumn{7}{|c|}{ Predictors of the BITSEA/P scores } & 0.338 & 0.318 \\
\hline PIR-GAS & -0.237 & 0.116 & -0.307 & -2.043 & 0.049 & $-0.473--0.001$ & & \\
\hline Mothers' BSI hostility & 0.636 & 0.223 & 0.410 & 2.727 & 0.010 & $0.161-1.110$ & & \\
\hline \multicolumn{7}{|c|}{ Predictors of the BITSEA/C scores } & 0.329 & 0.287 \\
\hline CARS & -0.439 & 0.107 & -0.581 & -4.102 & $<0.001$ & $-0.657--0.221$ & & \\
\hline
\end{tabular}

BITSEA/P: Brief Infant and Toddler Social Emotional Assessment/ Problem Subscale, BITSEA/C: Brief Infant and Toddler Social Emotional Assessment/ Competence Subscale, PIR-GAS: Parent-Infant Relationship Global Assessment Scale, BSI: Brief Symptom Inventory, CARS: Childhood Autism Rating Scale.

children with ASD are limited [22]. Our results showed the increasing effect of maternal hostility on behaviour and emotional problems in young children with ASD. Previous studies have increasingly suggested a mediating role of parental negative emotional reactions for the relationship between child behaviour problems and parental stress $[23,24]$. Because hostility is closely related with negative emotionality, our results may be regarded as being in line with these studies.

A growing number of studies have pointed out the importance of the parent-child relationship on developing children in the non-ASD population $[25,26]$. Though ASD is related to poor patterns of parent-child interactions [27], the impact of parent-child relationships on behaviour outcomes in children with ASD is not well understood, especially in early ages. The results of this study showed that poor mother-child relationships have an independent increasing effect on the severity of emotional and behavioural symptoms in young children with ASD. Therefore, identifying motherchild relationship problems may be important for the management of the symptoms in these children.

The strength of our study is the inclusion of only newly-diagnosed treatment-naive patients, which was done to rule out the potential effects of interventions on emotional and behavioural profiles. Limitations of the present study include the small sample sizes and having a single assessment point. With a larger sample, it would have been possible to examine the relationships of more child- and parent-related factors with emotional and behavioural profiles of children. With longitudinal assessments of child- and parentrelated variables, it would be possible to determine the direction of the effects between a child's emotional and behavioural problems and parental factors.

\section{CONCLUSIONS}

Findings from this study suggest that a reduction of maternal hostility and an improvement in the mother- child relationship may have a potential to ameliorate a child's emotional and behavioural problems in early life. Because behavioural and emotional problems in children with ASD usually persist into adolescence and young adulthood [28], understanding the risk factors at the early ages may have potential implications for longterm outcomes. Overall, clinicians treating young children with ASD need to assess the maternal psychiatric status and the mother-child relationships while treating the coexisting psychiatric problems of the children.

\section{CONFLICT OF INTEREST}

The author(s) declared no potential conflicts of interest with respect to the research, authorship, and/or publication of this article.

\section{AUTHOR CONTRIBUTORSHIP}

Ayhan Bilgiç have made substantial contributions to the design, acquisition and analysis of data, literature search, and in drafting the article. Necati Uzun have made substantial contributions to the acquisition of data and literature search.

\section{REFERENCES}

[1] Gadow KD. Comparison of DSM-IV symptoms in elementary school-age children with PDD versus clinic and community samples. Autism [Internet] 2005; 9(4): 392-415. https://doi.org/10.1177/1362361305056079

[2] Kaat AJ, Gadow KD, Lecavalier L. Psychiatric symptom impairment in children with autism spectrum disorders. Journal of Abnormal Child Psychology 2013; 41(6: 959-969.

[3] Gadow KD, DeVincent C, Schneider J. Predictors of psychiatric symptoms in children with an autism spectrum disorder. J Autism Dev Disord 2008; 38(9): 1710-20. https://doi.org/10.1007/s10803-008-0556-8

[4] Magiati I, Tay XW, Howlin P. Cognitive, language, social and behavioural outcomes in adults with autism spectrum disorders: A systematic review of longitudinal follow-up studies in adulthood. Clin Psychol Rev [Internet] 2013; 34(1): 73-86.

https://doi.org/10.1016/j.cpr.2013.11.002 
[5] Machado Junior SB, Celestino MI, Serra JP, Caron J, Pondé MP. Risk and protective factors for symptoms of anxiety and depression in parents of children with autism spectrum disorder. Dev Neurorehabil 2016; 19(3): 146-53.

[6] Zablotsky B, Anderson C, Law P. The association between child autism symptomatology, maternal quality of life, and risk for depression. J Autism Dev Disord 2013; 43(8): 194655.

https://doi.org/10.1007/s10803-012-1745-Z

[7] Tonge BJ, Bull K, Brereton A, Wilson R. A review of evidence-based early intervention for behavioural problems in children with autism spectrum disorder: the core components of effective programs, child-focused interventions and comprehensive treatment models. Curr Opin Psychiatry 2014; 27(2): 158-65. https://doi.org/10.1097/YCO.0000000000000043

[8] Puckering C, Allely CS, Doolin O, Purves D, McConnachie A, Johnson PC, Marwick H, Heron J, Golding J, Gillberg C, Wilson P. Association between parent-infant interactions in infancy and disruptive behaviour disorders at age seven: a nested, case-control ALSPAC study. BMC Pediatr 2014; 14: 223.

https://doi.org/10.1186/1471-2431-14-223

[9] Marwick H, Doolin O, Allely CS, McConnachie A, Johnson P, Puckering C, Golding J, Gillberg C, Wilson P. Predictors of diagnosis of child psychiatric disorder in adult-infant socialcommunicative interaction at 12 months. Res Dev Disabil 2013; 34(1): 562-72.

https://doi.org/10.1016/j.ridd.2012.09.007

[10] Wan MW, Green J, Elsabbagh M, Johnson M, Charman T, Plummer F. BASIS Team. Quality of interaction between atrisk infants and caregiver at $12-15$ months is associated with 3-year autism outcome. J Child Psychol Psychiatry 2013; 54(7): 763-71.

https://doi.org/10.1111/jcpp.12032

[11] Briggs-Gowan M, Carter A, Irwin J, Wachtel K, Cicchetti D. The Brief-Infant Toddler Social and Emotional Assessment: screening for social emotional problems and delays in competence. J Pediatr Psychol 2004; 29(2): 143-55. https://doi.org/10.1093/jpepsy/jsh017

[12] Karabekiroglu K, Rodopman-Arman A, Ay P, Ozkesen M, Akbas S, Tasdemir GN, et al. The reliability and validity of the Turkish version of the brief infant-toddler social emotional assessment (BITSEA). Infant Behav Dev [Internet] 2009; 32(3): 291-7. https://doi.org/10.1016/j.infbeh.2009.03.003

[13] Derogatis LR. The Brief Symptom Inventory (BSI): Administration, scoring \& procedures manual-II. Clinical Psychometric Research; 2nd ed edition 1992.

[14] Şahin N, Nesrin H, Durak A. Kısa semptom envanteri: Türk gençleri için uyarlanması. Türk Psikoloji Dergisi 1994; 9(31): 44-56.

[15] Schopler E, Reichler RJ, DeVellis RF, Daly K. Toward objective classification of childhood autism: Childhood Autism Rating Scale (CARS). J Autism Dev Disord [Internet] 1980; 10(1): 91-103 https://doi.org/10.1007/BF02408436
[16] Sucuoğlu B. The Psychometric Characteristics of the Turkish form of the Aberrant Behavior Checklist. Turkish J Psychol 2003;18: 93-96.

[17] Savasir I, Sezgin N, Erol N. Ankara Gelişim Tarama El Kitabı. 1st ed. Türk Psikologlar Dernegi 1994.

[18] Three Z to. Diagnostic Classification of Mental Health and Developmental Disorders of Infancy and Early Childhood, (DC: 0-3R). National Center for Clinical Infant Programs; Revised edition 2005.

[19] Baker JK, Smith LE, Greenberg JS, Seltzer MM, Taylor JL. Change in Maternal Criticism and Behavior Problems in Adolescents and Adults with Autism Across a Seven-Year Period. J Abnorm Psychol 2011; 120(2): 465-75. https://doi.org/10.1037/a0021900

[20] Greenberg JS, Seltzer MM, Hong J, Orsmond GI. Bidirectional effects of expressed emotion and behavior problems and symptoms in adolescents and adults with autism. Am J Ment Retard [Internet] 2006; 111(4): 229-49. https://doi.org/10.1352/08958017(2006)111\%5B229:BEOEEA\%5D2.0.CO;2

[21] Simonoff E, Jones CRG, Baird G, Pickles A, Happé F, Charman $T$. The persistence and stability of psychiatric problems in adolescents with autism spectrum disorders. $J$ Child Psychol Psychiatry Allied Discip 2013; 54(2): 186-94. https://doi.org/10.1111/j.1469-7610.2012.02606.x

[22] Baker JK, Messinger DS, Lyons KK, Grantz CJ. A Pilot Study of Maternal Sensitivity in the Context of Emergent Autism. J Autism Dev Disord [Internet] 2010; 40(8): 988-99. https://doi.org/10.1007/s10803-010-0948-4

[23] Hastings RP, Kovshoff H, Ward NJ, Degli Espinosa F, Brown $\mathrm{T}$, Remington $\mathrm{B}$. Systems analysis of stress and positive perceptions in mothers and fathers of pre-school children with autism. J Autism Dev Disord 2005; 35(5): 635-44. https://doi.org/10.1007/s10803-005-0007-8

[24] Lecavalier L, Leone S, Wiltz J. The impact of behaviour problems on caregiver stress in young people with autism spectrum disorders. J Intellect Disabil Res 2006; 50(3): 17283.

https://doi.org/10.1111/j.1365-2788.2005.00732.x

[25] Flouri E, Midouhas E, Joshi $\mathrm{H}$, Tzavidis N. Emotional and behavioural resilience to multiple risk exposure in early life: the role of parenting. Eur Child Adolesc Psychiatry [Internet] 2014; 745-55.

[26] Platt R, Williams SR, Ginsburg GS. Stressful Life Events and Child Anxiety: Examining Parent and Child Mediators. Child Psychiatry Hum Dev 2016; 47(1): 23-34. https://doi.org/10.1007/s10578-015-0540-4

[27] Beurkens NM, Hobson JA, Hobson RP. Autism severity and qualities of parent-child relations. J Autism Dev Disord 2013; 43(1): 168-78.

https://doi.org/10.1007/s10803-012-1562-4

[28] Gray KM, Keating CM, Taffe JR, Brereton A V., Einfeld SL, Reardon TC, et al. Adult Outcomes in Autism: Community Inclusion and Living Skills. J Autism Dev Disord [Internet] 2014; 44(12): 3006-15.

https://doi.org/10.1007/s10803-014-2159-x 